\title{
Kreative Lösung
}

- Was ist in Ihrem ergotherapeutischen Verständnis ein Hilfsmittel? Für manche Menschen im hochtechnisierten Japan ist es ein Roboter, der sie im Altag entlastet. Putzen, saugen, spülen - mit Twendy-One alles kein Problem. Damit nicht genug: Ebenfalls in Japan entwickelten Forscher eine intelligente Prothese. Der lernfähige Roboterarm passt sich dem Menschen an und nicht umgekehrt. Klientenzentrierung im Hightech-Zeitalter.

_ Hierzulande greifen wir eher auf „bodenständige“ Helfer zurück. Spontan haben Sie bei meiner Frage sicherlich an Einhänderbretter, Griffverdickungen oder Strumpfanzieher gedacht. Aber auch Schienen gehören zum ergotherapeutischen Hilfsmittelrepertoire. Wir bieten unseren Klienten kreative und individuell angefertigte Lösungen an. Ein Beispiel sind Griffverdickungen aus Moosgummi. Schnell bereitgestellt und vielseitig einsetzbar für Besteck, Stifte und andere Gegenstände, die man gut im Griff haben möchte.

- Wir können uns als Experten betrachten. Unsere Ausbildung bereitet uns darauf vor, welche Hilfsmittel unsere Klienten im Alltag unterstützen oder deren verloren gegangene Funktionen substituieren. Die Ergotherapie ist der einzige Gesundheitsfachberuf, für den Hilfsmittelberatung und Hilfsmitteltraining in den Heilmittelrichtlinien gesetzlich verankert sind. Nutzen wir also unsere Expertise, um sie in transdisziplinären Teams einzubringen. Und um unsere Klienten optimal und professionell zu versorgen! Und wer weiß? Vielleicht sind wir bald selbst gemeinsam mit Produktdesignern an der Entwicklung von Hilfsmitteln beteiligt...

Viele kreative Hilfsmittelideen wünscht Ihnen Ihre

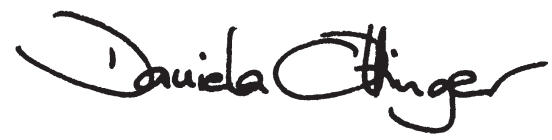

PS: Wie handhaben Sie es mit der Hilfsmittelversorgung? Stellen Sie kleinere Hilfsmittel selbst her oder verweisen Sie Ihre Klienten an Sanitätshäuser? Auf einen Erfahrungsaustausch mit Ihnen freue ich mich!

ZU GEWINNEN

\section{Fortbildung im Allgäu}

Diesmal verlosen wir den dreitägigen Kurs „Psychopathologie und Psychopharmaka" vom 6. bis 8.7.2009 im Bildungswerk Irsee, und zwar inklusive Unterkunft und Verpflegung. Schicken Sie einfach eine Postkarte mit dem Stichwort „Kloster“ an die Redaktion. Viel Glück! 